\title{
Religious Diversity and Conceptual Schemes: Critically Appraising Internalist Pluralism
}

\author{
Mikel Burley ${ }^{1}$ (D)
}

Published online: 9 February 2018

(C) The Author(s) 2018. This article is an open access publication

\begin{abstract}
Is a philosophical theory needed to 'underwrite' attitudes of toleration and respect in a multicultural and religiously diverse world? Many philosophers of religion have thought so, including Victoria Harrison. This article interrogates Harrison's theory of internalist pluralism, which, though offering a welcome alternative to other theories, such as John Hick's 'pluralistic hypothesis', nevertheless faces problems. Questioning the coherence of the theory's account of how the existence of objects of worship can avoid being fully conceptual-scheme dependent, and raising doubts about its pretensions to promote interreligious harmony, I also critically discuss the common philosophical tendency to work with under-described and insufficiently analysed examples. What philosophy ought to be able to offer in relation to religious diversity, I propose, is attentiveness to nuances and particularities, thereby aiding religious understanding without the need for a general theory.
\end{abstract}

Keywords Religious diversity · Internalist pluralism · Conceptual schemes · Victoria Harrison · Interreligious disagreement

Many philosophers believe that philosophy's business is to devise theories in order to explain aspects of the world in which we live. So, when confronted with the phenomenon of religious diversity, philosophers of religion often treat it as a problem to be solved, and hence go looking for a theory to solve it. In the rush to find a theory, the task of articulating what the problem is supposed to be is frequently underexplored. For example, Victoria Harrison writes as follows:

As societies become increasingly multicultural, there progressively arises a need for an appropriate theory that is capable of making sense of the various difficulties presented by religious diversity. To be precise, what seems to be required at

Mikel Burley

m.m.burley@leeds.ac.uk

1 School of Philosophy, Religion and History of Science, University of Leeds, Leeds LS2 9JT, UK 
this historical juncture is a theory of religious pluralism that is suitably sensitive to the challenge posed by cultural diversity, while remaining respectful of religious differences. $\left(2006\right.$, p. 287) ${ }^{1}$

Here we are told that religious diversity presents us with 'various difficulties' and that these difficulties generate the need for a theory that can make sense of them. But what are those difficulties, and why should a philosophical theory be needed?

From a careful reading of Harrison's work, it appears that the main difficulty she has in mind is the phenomenon of interreligious disagreement. The fact that, on the face of it, adherents of different religions appear to disagree on many matters - including not only religious doctrines but also more immediately practical issues of how to liveraises the question of how to get along with one another without the disagreements degenerating into conflict and violence. In short, Harrison is eager to promote 'religious toleration' (2008, p. 109) and 'equal respect [for] all ethical and religious belief systems' (2012, p. 84). So her task is to construct a theory that will 'underwrite the appropriateness' of interreligious toleration and respect (2008, p. 109) - and to do so by showing how it can be the case that apparently contradictory beliefs might all be true.

Personally speaking, I am in favour of promoting mutual respect between people in general, including those whose religious or nonreligious affiliations diverge from one another's. If philosophy has any role to play in that project, it is, or should be, the role of exemplifying how a deepened understanding of diverse religious and nonreligious forms of life (or perspectives, worldviews, belief systems) may be arrived at. That deepening of understanding is unlikely to always lead to enhanced tolerance and respect. There is no reason in principle why it should not sometimes lead to an accentuation of hostility; for in some instances, the more one learns about a given form of life, the more one may come to deplore it. A view of philosophy that prioritises understanding and elucidation will thus not inevitably constitute a tool for fostering harmony and irenic benevolence among people of divergent positions. But it stands a chance of enabling residual disputes and conflicts to be based more on genuine disagreement than on ignorance.

The purpose of this article is twofold. One purpose is to critically engage with Harrison's proposed theory of religious diversity, which she calls internalist pluralism. In brief, this theory contends that apparent disagreements between members of different religions are not, at least for the most part, genuine disagreements at all; they are instead mere differences that emerge from distinct conceptual schemes, ${ }^{2}$ a conceptual scheme

\footnotetext{
${ }^{1}$ See also Harrison (2012, pp. 71-72): 'In our increasingly multicultural society there is an urgent need for a theory that is capable of making sense of the various philosophical difficulties presented by ethical and religious diversity — difficulties that, at first sight, seem to be remarkably similar.'

${ }^{2}$ I am borrowing the terminology of a difference versus a disagreement from Harrison, who repeatedly affirms that her internalist pluralist theory can 'acknowledge the genuine differences between religious [and/or moral] traditions' (2006, p. 300; cf. 2012, p. 86) while regarding these as 'mere' differences rather than competing truth claims (e.g. 2012, p. 79). I take the implication here to be that a 'mere difference' does not amount to a genuine disagreement.
} 
being the 'general system of concepts with which we organize our thoughts and perceptions' (Blackburn 1994, p. 72, quoted in Harrison 2008, p. 98 fn. 4) ) $^{3}$-where 'our' may refer either to human beings in general or to some particular community or group. As will become evident, I am doubtful about the coherence of Harrison's proposal, both as a theory and as a means for purportedly advancing interreligious tolerance or respect. The other main purpose of this article is the constructive one of demonstrating how the practice of philosophy of religion in general, and of philosophy of religious diversity in particular, might be improved by means of a more rigorous and attentive analysis of examples than is commonly displayed in the literature. To this end, I shall be picking up a number of the examples that Harrison briefly adumbrates and showing how consideration of alternative interpretive possibilities helps us to avoid hasty overgeneralising conclusions. When the richness and complexity of human interactions are attended to, understanding may be enabled to deepen without our being distracted by certain unhelpful assumptions, such as the assumption that a philosophical theory is needed to 'underwrite' interreligious communication, mutual understanding and respect.

\section{Harrison's Internalist Pluralism}

Philosophical and theological debates over religious diversity have, since the early 1980 s, routinely been framed in terms of a threefold typology of theoretical positions, namely exclusivism, inclusivism and pluralism. ${ }^{4}$ Despite scepticism from several quarters concerning its viability, the typology has for the most part remained in place. ${ }^{5}$ One of the common complaints about the typology is that it tends to oversimplify the range of theoretical options available. In the case of pluralism in particular, discussions have generally been fixated on the version of religious pluralism - or 'the pluralistic hypothesis' - advocated by John Hick (see esp. Hick 1995, 2004). This fixation has drawn attention away from the work of other proponents of pluralism, whose respective theories differ from Hick's to a greater or lesser extent. ${ }^{6}$ Among these others is Victoria Harrison, who has advocated the theory that she terms internalist pluralism in a number of publications from 2000 onwards. $^{7}$

Harrison appropriates the term 'internalism' from Hilary Putnam, who, in what is sometimes referred to as his middle period, championed a theory called internal realism. ${ }^{8}$ Notwithstanding Putnam's own subsequent modifications and partial

\footnotetext{
${ }^{3}$ Following Harrison, I have here quoted from the first edition of Simon Blackburn's dictionary. In the second and third editions, there is a shift in the attribution of agency. No longer is it 'we' who 'organize our thoughts and perceptions' with the 'system of concepts'; instead, it is the concepts themselves that 'shape or organize our thoughts and perceptions' (Blackburn 2005, p. 70; 2016, p. 95). Though intriguing, this shift is not something I have space to pursue here.

${ }^{4}$ The typology was first proposed by Race (1983).

${ }^{5}$ For discussion of criticisms and a defence of the typology, see Schmidt-Leukel (2005).

${ }^{6}$ For a selection of pluralist positions, see Knitter (2005). See also Byrne (1995), Heim (1995) and Griffin (2005). A concise comparative overview of some of these theories is presented in Ruhmkorff (2013).

${ }^{7}$ See esp. Harrison (2000, 2006, 2008, 2012).

${ }^{8}$ For talk of Putnam's 'middle period', see for example Norris (2002, esp. chs 3 and 4) and Cormier (2015, pp. 803-805). Putnam later came to refer to this internal realism as 'pragmatic realism' (1987, p. 17) and as "realism with a small "r"' (1992a, pp. 26-29).
} 
disavowals of internal realism (see, e.g. Putnam 1994a, pp. 242-254; 1994b), Harrison treats it as a live theoretical option. Although internal realism is itself a metaphysical theory, Putnam defines it in opposition to what he calls 'metaphysical realism', the latter comprising the following three theses: first, that 'the world consists of some fixed totality of mind-independent objects'; second, that '[t]here is exactly one true and complete description of "the way the world is", ; and third, that "[t]ruth involves some sort of correspondence relation between words or thought-signs and external things and sets of things' (Putnam 1981, p. 49). The perspective of metaphysical realism can, Putnam proposes, be designated as 'the externalist perspective, because its favorite point of view is a God's Eye point of view' (p. 49). This is to be contrasted with 'the internalist perspective', according to which the question 'what objects does the world consist of?' makes sense only 'within a theory of description' (p. 49, Putnam's emphasis).

Interchangeably with the term 'theory of description', Putnam also uses the term 'conceptual scheme'. He remarks, for example, that on the internalist view, 'a sign that is actually employed in a particular way by a particular community of users can correspond to particular objects within the conceptual scheme of those users' (p. 52, Putnam's emphasis) _ but not outside it. Indeed, on this view, it makes no sense to suppose that objects could exist as objects independently of any conceptual scheme, for it is the conceptual scheme (or 'theory of description' or 'scheme of description') that divides up the world into distinguishable objects. While some commentators would construe this as a form of nonrealism or antirealism, Putnam calls it internal realism because it maintains that the objects we, as individuals, perceive and think about do really exist independently of our own thoughts and perceptions, albeit not independently of the conceptual scheme within which our perceiving and thinking are occurring.

Taking up Putnam's internal realism, Harrison applies it to religions. In one article, she also applies it to systems of ethical values (Harrison 2012), though it is primarily on what she says about religions that I shall be focusing. Central to Harrison's appropriation of Putnam's theory is her contention that if 'there is no way of intelligibly discussing what exists in a manner that is conceptual-scheme neutral', then 'the existence of purported religious realities can only be meaningfully discussed within a particular conceptual scheme or, what we might call, a "faith-stance"' (Harrison 2006, p. 292). ${ }^{9}$ The use of the term 'faith-stance' enables Harrison to avoid committing herself to the view that religions themselves constitute distinct conceptual schemes. She prefers instead to regard religions as being 'composed of overlapping conceptual schemes' (2012, p. 76), and the term 'faith-stance' allows this measure of flexibility. ${ }^{10}$ From the claim that intelligible talk of religious realities is always internal to a

\footnotetext{
${ }^{9}$ Harrison initially adopted the term 'faith-stance' in the context of discussing Hans Urs von Balthasar's theology in her doctoral dissertation (1997). See also Harrison (1998, p. 86).

${ }^{10}$ Arguably, Harrison thus evades the force of Terry Godlove's argument against the coherence of claiming that religions can be 'wholly incompatible' (Godlove 1984, p. 302; 1989, pp. 117-118). Godlove's argument, which draws heavily on Davidson (1974), is a general one against even the logical possibility of such incompatibility. In brief, my own view on this particular point is that, first, it remains unclear what would count as thorough incompatibility, and second, since Godlove denies the very coherence of the idea of such incompatibility, he has precluded any possibility of an explanation of what it would amount to. But it is not my intention to enter into further discussion of Godlove's position here.
} 
conceptual scheme or faith-stance, it follows that the very concepts of certain religious realities are untranslatable from one faith-stance to another. ${ }^{11}$ In other words, different religious communities, insofar as they assume different faith-stances and hence operate with different conceptual schemes, will not be able to understand one another's religious beliefs. Thus, Harrison contends, this theory gives us a form of religious pluralism-internalist pluralism - that avoids both eliminativism and reductivism (2015, p. 267). The theory is non-eliminativist inasmuch as it eschews the denial of there being any objective reality corresponding to the beliefs and concepts of the various religions. And it is non-reductive in that it does not assert that the beliefs and concepts of all religions, or of all faith-stances, correspond to the same objective reality; rather, the theory allows for a plurality of such realities, albeit that they are 'objective' only in the sense that, internal to a given conceptual scheme, their reality is not dependent on any individual member of the community that operates with that scheme. There is still, however, a sense in which the reality of anything, including objects of religious faith and worship, is dependent upon a given conceptual scheme, and on the face of it, this is likely to strike many religious believers as an unacceptable implication of the theory. It is likely to appear unacceptable because it seems to suggest that objects of religious faith are mere conceptual constructs. To deal with this issue, Harrison introduces a distinction between 'conceptual-scheme targetability' and 'successful conceptual-scheme targeting' (2008), which I shall outline below.

If I have understood Harrison correctly, for an object to be conceptual-scheme targetable is merely for it to be conceptualised within the conceptual scheme in question. It is its conceptualisation - that is, the fact of there being a concept of that object - that makes the object a possible target for belief. Thus, for example, the concept of nirvāna has a place within the conceptual schemes of various Buddhist traditions, thereby making nirvāna a possible object - a targetable object — of belief for people who operate with (or 'subscribe to', as Harrison often puts it) one or other of the Buddhist conceptual schemes. For an object to be successfully targeted within a given conceptual scheme, meanwhile, is for it to be the case that not only does the conceptual scheme in question have a concept of that object, but there is in fact - in reality - an object to which the concept corresponds. To illustrate the point, Harrison adduces a simplified nonreligious imaginary example. She invites us to envisage 'a world in which there are three large plants' (Harrison 2008, p. 102). Someone employing a conceptual scheme that possesses the concept of a tree but lacks any distinction between elm trees and beech trees, 'would see a world containing three trees, which he regards as large plants'. By contrast, someone whose conceptual scheme includes a distinction between elms and beeches 'would see a world containing, for example, one elm and two beeches'. Harrison then adds the following remarks:

The question of whether, along with the first person, we subscribe to a conceptual scheme that just identifies trees or, along with the second person, we subscribe to a conceptual scheme that identifies elms and beeches is quite distinct from the

\footnotetext{
${ }^{11}$ Harrison is somewhat equivocal on the issue of translatability. Sometimes, she endorses 'the idea that there can be no translation of meaning from one conceptual scheme into another' (2012, p. 82 fn. 33), whereas elsewhere she implies that anyone who has been sufficiently 'immerse[d]' in two or more conceptual schemes would be capable of translating from one to the other (e.g. Harrison 2006, p. 299). The difficulties of interpretation that these equivocations generate will be brought out in my discussion.
} 
question of whether or not there are any large plants. The latter is, in this example, not simply conceptual-scheme dependent in the way in which the question of whether there are just trees or whether there are elms and beeches is wholly a matter of the choice of conceptual scheme. (Harrison 2008, p. 102)

Harrison's point appears to be that, despite the differences between their respective conceptual schemes, both of the individuals in the example can be regarded as having successfully targeted the objects that Harrison describes as three large plants. The success consists in the fact that the concepts with which each of the individuals is operating apply to the objects in question and, furthermore, the objects in question - the three large plants - really are there to be targeted, independently of the concepts being applied to them from within specific conceptual schemes. So, in other words, each of the conceptual schemes represented in the example contains concepts that make the three large plants targetable, and the application of the concepts to the plants, coupled with the fact that the plants themselves are not conceptual-scheme dependent, results in both individuals having successfully targeted the objects. ${ }^{12}$ There is, however, a difficulty in making this part of the theory consistent with Harrison's overall commitment to internalist pluralism. I shall discuss that difficulty in the next section before turning to a more general issue that I have with the way in which Harrison works with illustrative examples.

\section{A Difficulty with the Internalist Pluralist Picture}

A brief recap: Harrison intends her theory of internalist pluralism to be acceptable to religious believers. Indeed, she intends it to be a useful intervention in debates over religious diversity, for she maintains that its acceptance would promote tolerance and even respect between different religious communities. Harrison is aware, however, that internalist pluralism is hardly likely to be accepted by religious believers if it is interpreted as portraying the very existence, or reality, of objects of religious faith and worship as being a mere artefact of conceptual schemes. The 'three large plants' analogy is intended to show how internalist pluralism can avoid that interpretation. But how is the analogy supposed to relate to a specifically religious, or multireligious, context? Harrison herself sketches the following example concerning Christian, Muslim and Hindu conceptions of the divine.

The Christian in Harrison's example believes in a triune God and also in the existence of angels and human beings. The Muslim, similarly, believes in angels and human beings, but believes Allāh to be unitarian. The Hindu, too, believes in angels (or in beings at least comparable to angels) and in humans but believes the ultimate divine principle to be Brahman, which is 'projected' as multiple deities, including the three divine forms (trimūrti) popularly known as Brahmā, Viṣnu and Śiva (Harrison 2008, pp. 105-106). According to Harrison, the respective conceptual schemes of

\footnotetext{
12 The phrase 'are not conceptual-scheme dependent' may need qualifying, depending on how one interprets Harrison's position. On one interpretation, it would mean 'are not dependent on any first-order conceptual scheme but are nevertheless dependent on a second-order "meta-conceptual" scheme'. We shall come to that issue in the next section.
} 
these three religious believers are what determine the differences between the three sets of beliefs, but it is not the case that the conceptual schemes determine whether the beliefs are true. 'For if,' Harrison writes, 'irrespective of which conceptual scheme is employed and what range of entities that scheme deems targetable, only human agents are in fact successfully targeted, the substantive religious claims of Muslims, Christians and Hindus are false' (2008, p. 106, my emphasis). A difficulty here is that of understanding what, on an internalist account, it means to speak of something's being 'in fact successfully targeted' by a certain concept or set of concepts. On the basis of my best attempt to make sense of Harrison's 'three large plants' example in the previous section, I interpret Harrison here to be asserting that if, independently of any conceptual scheme, there are no divine or angelic 'agents', then there is no God or supreme divine principle and neither are there any angelic beings, and hence regardless of what any religious conceptual scheme deems to be targetable, the concepts pertaining to anything divine or angelic will miss their target-because there is no target to be hit.

Harrison might protest that 'irrespective of which conceptual scheme is employed' is not equivalent to 'independently of any conceptual scheme'. She might propose that it makes no sense to suppose that a given being or type of being exists or does not exist independently of all conceptual schemes, for 'the existence of purported religious realities can only be meaningfully discussed within [some] conceptual scheme' (Harrison 2006, p. 292). To spell out what is meant by 'irrespective' in this context, Harrison might then appeal to the notion of a 'meta-conceptual scheme', for in some places this is what she identifies her internal pluralist theory as being (e.g. Harrison 2006, pp. 299-300). This appeal would enable Harrison to say that 'irrespective of which conceptual scheme is employed' should be understood to mean 'irrespective of which first-order conceptual scheme is employed'; if the objects or agents in question exist within, or from the perspective of, a second-order meta-conceptual scheme, such as internal pluralism, it is precisely this fact that enables us to declare that they exist 'irrespective of which [first-order] conceptual scheme is employed'. According to this interpretation of Harrison's view — which she does not herself state explicitly_it would be the existence of human agents combined with the non-existence of any divine or angelic beings within a meta-conceptual scheme that would make it the case that 'only human agents are in fact successfully targeted' by Muslims, Christians and Hindus.

There are, however, two main problems with this attempt to make sense of Harrison's position. One problem derives from Harrison's recommendation that conceptual schemes be regarded as faith-stances. Since a philosophical theory such as internalist pluralism is not itself a faith-stance, such theories might be deemed to fall outside of Harrison's category of conceptual schemes. This problem would be relatively easy to rectify: Harrison could merely revoke her insinuation that 'faith-stance' is equivalent to 'conceptual scheme' and instead propose that faith-stances are one type of conceptual scheme and philosophical theories are another. The second problem is harder to resolve. It is that the interpretation of Harrison's position that I offered above fails to clarify why, for any given class of objects or beings, it should be the fact that this class is deemed to exist from within a meta-conceptual scheme that determines whether members of that class are 'successfully targeted' by the concepts of the firstorder conceptual schemes that are under examination by someone operating with the meta-scheme. 
The upshot of my discussion in this section could be expressed in terms of a dilemma for internalist pluralism. Either (a) the notion of a concept's failing to successfully target anything 'irrespective of which conceptual scheme is employed' means that, irrespective of all first-order conceptual schemes, there exists no such target in a given meta-conceptual scheme (such as the theory of internalist pluralism), or (b) 'irrespective of which conceptual scheme' means, in this context, simply 'independently of any conceptual scheme'. If we opt for '(a)', then we face the problem of its being unclear why any meta-conceptual scheme should be deemed capable of determining whether certain things do or do not exist for first-order conceptual schemes. But if we opt for '(b)', then it looks as though what began as internal realism has collapsed into the very externalism, or metaphysical realism, that Harrison wanted to abjure. This is because, according to '(b)', the issue of whether the concepts - including, of course, the specifically religious concepts - of a religious community (or those who adopt some particular faith-stance) succeed in 'targeting' anything real is dependent on what is 'in fact' the case, where the facts of the matter are supposed to be independent of all conceptual schemes.

In the light of my discussion above, it is pertinent to observe that, were we to opt for the second horn of the dilemma that I have identified, we would end up with a picture that is comparable to the one that John Hick advocates, which Harrison terms 'transcendental pluralism' (e.g. Harrison 2006, pp. 295-301; 2013, pp. 484-487). She calls it transcendental because it postulates a noumenal 'Real' that transcends human conceptual capacities. By Hick's lights, this transcendent or 'transcategorial Real' eludes description by any conceptual scheme and yet is that towards which every religion's (or every 'great' religion's) conception of a divine or other supreme principle is directed (Hick 2004, esp. pp. xvii-xlii, pp. 231-296). Although Harrison's talk of 'agents' is at a lower level of abstraction than Hick's talk of 'the Real', what option '(b)' would give us is a view that amounts to one closely resemblant of Hick's realism. In other words, it gives us the view that what makes it possible to deny that conceptions of the divine — such as the Trinity, Allāh, Brahman, et al.—must be purely conceptual constructs is the fact that their truth or falsity is determined by their targeting, or failing to target, something that is not itself dependent on the conceptual scheme to which they belong. This, as I have contended, appears to be the picture we are offered when Harrison is defending internalist pluralism against the charge that it allows the existence of objects of religious faith and worship to be determined solely by the conceptual schemes themselves. However, when Harrison is presenting examples to illustrate how internalist pluralism enables apparent religious disagreements to be reconstrued as mere religious differences, we get a very different picture. As will become clear in the next section, I consider Harrison's way of working with examples to be unsatisfactory both for substantiating her particular position and as an argumentative strategy more generally. In this respect, however, she is far from alone in contemporary philosophy.

\section{Working with Examples}

There is a tendency within analytic philosophy in general, from which analytic philosophy of religion is far from immune, to illustrate arguments with examples that are thinly sketched and poorly contextualised. Discerning readers of such arguments, if 
they can make any sense of the examples at all, could be excused for wondering what purpose the examples are intended to serve and whether, in the absence of thicker description, they really serve any useful purpose whatsoever. Unfortunately, the examples adduced in Harrison's arguments on behalf of internalist pluralism, though ostensibly intended to show how the theory facilitates the dissolution of interreligious disputes, are of the thin and under-contextualised variety. Examining the weaknesses of a selection of them will, I propose, provide a useful starting point for reflecting on an alternative approach to philosophy of religion: an approach that invokes and dwells with examples long enough to learn what they have to teach us, as opposed to treating them as mere decoration for a line of argument that owes little if anything to the examples' particularities. This largely critically focused article is not the place to flesh out that alternative approach in full, but I have begun to do so elsewhere. ${ }^{13}$

Among the relatively few examples that Harrison deploys to illustrate apparent interreligious disagreements are the following two. First is the case of Śaivite Hinduism vis-à-vis Roman Catholicism. Within the Śaivite conceptual scheme, Śiva 'is a real, objectively existing God', whereas in the Catholic scheme, God is the Trinity comprising Father, Son and Holy Spirit. Observing that internalist pluralism allows us to acknowledge these differences, Harrison adds that what the theory does not allow us to do is to 'intelligibly discuss the qualities of, for example, Śiva from within a conceptual scheme, such as a Christian one, in which Śiva occupies no place' (2006, p. 293). ${ }^{14}$ What this is supposed to illustrate is that, from the perspective of internalist pluralism, the Catholic is in no position to oppugn the god of Saivism and neither is the Saivite in a position to oppugn the god of Roman Catholic Christianity. The conceptual-scheme dependence of these respective conceptions of God is considered by Harrison to facilitate a sense in which both might be true - that is, true within the relevant conceptual scheme - and to thereby delegitimise any denunciation of one or the other as false.

The second of Harrison's examples is that 'of a Christian asserting that Jesus is the Son of God, and a Muslim replying: "No, he isn't!"' Despite appearances, the two may in fact not be in disagreement, 'but merely talking past each other' (2006, p. 293; 2012, p. 80). Harrison notes that the situation might be compared to that in which one logician describes three atoms as a set of three objects while another logician describes the same atoms as a set of seven objects. Although the logicians appear to be disagreeing, what is really the case is that the second logician's conceptual scheme allows pairs and trios (and other mereological sums) as well as single atoms to count as objects in their own right, whereas the first logician's conceptual scheme counts only single atoms as objects. $^{15}$

Harrison's treatments of both the Śaivite and Catholic case and the Christian and Muslim case raise more questions than they address. Why, for example, should we suppose that it would be unintelligible to discuss the qualities of Siva from within a non-Śaivite conceptual scheme? If I, or Harrison herself, were to be teaching a class on Hindu representations of the divine, then among the topics we would be discussing are

\footnotetext{
${ }_{13}^{13}$ See, for example, Burley (2017a, b, 2018).

${ }^{14}$ Virtually the same example occurs in Harrison (2012, p. 79). I have, incidentally, amended the transliteration of the name Siva.

${ }^{15}$ Harrison borrows the three-atoms example from Putnam (1987, pp. 18, 32-35; 1992b, p. 120).
} 
the qualities that are typically attributed to Śiva by Śaivite Hindus. The fact that an academic course within a secular educational institution is operating with a conceptual scheme other than that of religious Śaivism need not vitiate all attempts at discussing Siva's qualities within that context. Harrison concedes that 'genuinely entering into' another's belief system or conceptual scheme would open up the possibility of intelligible interreligious dialogue, and hence also of interreligious dispute, about issues such as the objectivity and truth of their respective claims (2006, p. 293 fn. 28). But Harrison admits that the notion of 'entering into' is vague. There are many ways in which one might learn about the concepts of another religion, including concepts relating to the religion's deity or supreme principle; and there are many degrees of learning. Clearly, it would be surprising if a Roman Catholic were to speak of Śiva with the air of reverence that a Śaivite might, but given a little training in Hindu theology, there would be nothing to stop the Catholic from conversing intelligibly about Siva's qualities. So the force of Harrison's initial claim about the impossibility of discussing those qualities from 'within', say, a Christian conceptual scheme becomes hazy. If all it means is that one could not intelligibly discuss something without having at least some understanding of that thing, the claim is at risk of seeming banal.

With regard to the Christian who affirms the divinity of Christ and the Muslim who denies this, on what grounds are we to say whether they are disagreeing with each other? Since, on the face of it, they do appear to be disagreeing, the onus is on those who deny that this is what is going on to show how it could be the case that the apparent disagreement is merely a difference. Harrison's analogy with the two logicians does not get us very far, for a difference in criteria for determining how many objects are constituted by three physical atoms is radically different from a context in which two people are disputing whether a certain human being is God incarnate. To even begin to get clear about what the latter dispute amounts to, we would have to gain some understanding of what it means for a Christian - and perhaps what it means for the particular Christian involved in the dispute - to believe in the divinity of Christ. For many Christians, this belief will be deeply embroiled with the attitude of veneration that goes along with regarding Christ as one's lord and saviour. To see what this means, one would have to look to the lives of those who proclaim it. It may turn out to mean many things, depending on who the proclaimer is. Perhaps this need for looking to the life is part of what Harrison is getting at by speaking of distinct conceptual schemes. The belief in Christ's divinity is enmeshed in a rich conceptual network: what Wittgenstein in one place refers to as 'a system of reference' or 'system of coordinates' (1980, p. 64e; 1998, p. 73e). 'Hence', Wittgenstein continues, 'although it's belief, it is really a way of living, or a way of judging life. Passionately taking up this interpretation' (1998, p. 73e). In short, one might say, the conceptual scheme is inseparable from the form of life that is being lived.

Pertinent to this issue is Wittgenstein's distinction between agreement in opinions and agreement in form of life (Wittgenstein 2009, §241). Deep religious disagreements are among the most obvious cases in which a disagreement in form of life is paramount. They are disagreements that could not, even in principle, be resolved by appeal to facts or evidence that both parties would readily accept. In his 'Lectures on Religious Belief', Wittgenstein gives the example of someone who believes in the Last Judgement and someone else who expresses doubt about it by saying 'Well, I'm not so sure. Possibly.' In such a case, Wittgenstein proposes, 'an enormous gulf' would exist 
between the speakers, whereas in a case where two people disagreed merely over the nationality of an aeroplane that was flying overhead, the conceptual distance between them would be relatively meagre (Wittgenstein 1966, p. 53). Wittgenstein's point may be understood in terms of the distinction between agreement (or disagreement) in opinions and agreement (or disagreement) in form of life. The disagreement over the nationality of the aeroplane is a matter of opinion, and it is not hard to imagine what evidence might be gathered in order to resolve the issue. The disagreement over the Last Judgement, however, is a disagreement in form of life: persuading one party or the other to change his or her view would require far more than merely a gathering of evidence of a sort that would, ab initio, be acceptable to both parties. Rather, what would be required is something as thoroughgoing as a religious conversion: coming to see the sense in a form of life that had previously been opaque to one.

So if we think of what Harrison means by different conceptual schemes in terms of what, in Wittgenstein's vocabulary, we might call different forms of life, there is certainly a sense in which the disagreement between a Christian and a Muslim over the divinity of Christ is apt to be thought of as such a difference. But to assert that it is therefore not really a disagreement at all is to go too far. The Muslim may have a deep understanding of what it means to regard Jesus Christ as God incarnate and to live one's life in accordance with that commitment. It may be precisely that commitment that the Muslim is rejecting. The disagreement may thus be one about how to live one's life. If that were the case, then it would certainly be a disagreement that goes deeper than a difference of opinion over an everyday matter of fact, but it would be a disagreement nonetheless. It is hard to see why Harrison thinks that merely by identifying it as a difference arising from divergent conceptual schemes, we somehow ease the path towards mutual toleration and respect. Toleration and respect may well be present, but not because the disagreement in form of life has been dissolved. It hasn't.

To take further these considerations about how to work with examples, let us now turn to another of the examples adduced by Harrison, which in this instance she borrows from D. Z. Phillips.

\section{Conceptual Schemes, Incomprehensibility and Respect}

It is central to Harrison's argument that 'the meanings of statements differ according to which conceptual scheme they are employed within' and that 'statements made within one conceptual scheme can thus be incomprehensible to those within another conceptual scheme' (2012, p. 82). Worth noting immediately is Harrison's use of the word 'can' here. That statements can be incomprehensible to someone operating with a different conceptual scheme implies that they are not necessarily incomprehensible. So mutual understanding across conceptual schemes is not being ruled out. But to illustrate the point that incomprehension does sometimes occur, Harrison borrows a passage from Phillips that is worth quoting in full:

If I hear that one of my neighbours has killed another neighbour's child, given that he is sane, my condemnation is immediate. (There are exceptions. See Faulkner's Requiem for a Nun.) But if I hear that some remote tribe practises child sacrifice, what then? I do not know what sacrifice means for the tribe in 
question. What would it mean to say that I condemned it when the 'it' refers to something I know nothing about? If I did condemn it I would be condemning murder. But murder is not child sacrifice. 'The ethical expression of Abraham's action is that he wished to murder Isaac: the religious expression is that he wished to sacrifice him.' (Phillips 1970, p. 237) ${ }^{16}$

Though the example is poignant, it is not immediately obvious how it relates to Harrison's point about the incomprehensibility of statements. In order to bring out the relevance, we might imagine that within the society where human sacrifice is practised, someone states or makes an inscription to the effect that the sacrifice of children is required in order to propitiate the gods. It is not far-fetched to suppose that declarations of this kind have been made in some societies, such as those of the Aztecs and Mayans of pre-Conquest Mesoamerica for example. ${ }^{17}$ One might then, following Phillips and Harrison, wonder whether, from one's present position in a contemporary western social context, one could readily understand this statement. If one cannot understand it, then one might, as Phillips does, feel at a loss to know how to form a moral evaluation of the sacrificial practices at issue.

It is important to recognise that it is by no means self-evident that an intimate understanding is impossible to achieve in this case. Achieving it may require time and effort. Sustained study of the historical and anthropological literature may be needed to acquaint oneself with the forms of life of the people who carried out the sacrifices and of those, including children, who were sacrificed. Also useful might be reflection upon the ritualistic dimensions of one's own life and of the lives of people in cultures with which one is already familiar - paying particular attention to the 'deep and sinister' aspects of certain ritual practices, as Wittgenstein does in some of his 'Remarks on Frazer's Golden Bough' (1993, esp. p. 147). As noted in the previous section above, Harrison allows for this kind of intercultural and interreligious understanding across conceptual schemes: 'internalist pluralism', she acknowledges, 'is not committed to the claim that one must become an adherent of a particular religious belief system before one can understand it' (2006, p. 293 fn. 28). So, again, the 'can' in the assertion that 'statements made within one conceptual scheme can ... be incomprehensible to those within another conceptual scheme' should certainly not be read as a 'must'.

Nor should we assume that the process of learning about and familiarising oneself with a particular society or culture would lead inevitably to a specific moral judgement. After coming to an enhanced understanding of what it means within the culture (or conceptual scheme or faith-stance) of the Mayan priesthood to hold child sacrifice to be necessary for propitiating the gods, some may feel that condemnation is inappropriate, whereas others may feel even more compelled than they did before to denounce the practices as morally repugnant. A response of this latter kind might be fortified by the knowledge that the people who were sacrificed were very far from being willing

\footnotetext{
${ }^{16}$ Most of this passage is quoted in Harrison (2012, p. 82 fn. 33), though Harrison omits the final sentence, which is itself a quotation from Kierkegaard (1939, p. 34). The very next clause of Kierkegaard's sentence, which is quoted neither by Harrison nor by Phillips, reads: 'and it is precisely here, in the contradiction of the two expressions of his desire, that lies dread, which may well rob one of one's sleep.'

${ }^{17}$ On Mayan sacrificial practices, see Siegel (1941, p. 65): 'Human sacrifice played a significant role among the "endless rites and ceremonies" required to supplicate and propitiate the gods. Besides sacrifice by tearing out the heart, men and girls were flung into pools of water to "propitiate the rain gods."
} 
victims, having normally, in the Mayan and Aztec cases for example, been taken captive during warfare (Sharer 1994, pp. 543-546; Purdum and Paredes 1989, p. 143). In cases where adults who were sacrificed appear to have volunteered, having regarded a sacrificial death as an honour and privilege, a different set of moral responses may be elicited. ${ }^{18}$ My point here is not to suggest that the moral judgements ought to go one way rather than the other, for the picture in almost any culture we care to examine is liable to be complicated. But the essential point here is that there is no reason to assume that differences in form of life-differences between conceptual schemes - invariably constitute an insuperable barrier to mutual understanding.

The purpose behind each of the examples of Harrison's that I have discussed, including the one borrowed from Phillips, appears to be to support the contention that where a high degree of incomprehension obtains, condemnation of or hostility towards the uncomprehended statement or practice is out of place. In the case of the Śaivite and the Roman Catholic, they must, on Harrison's account, refrain from trying to discuss each other's god unless they are somehow able to enter into the other's conceptual scheme. Whatever they do, however, they should respect each other. In the case of the Christian and the Muslim who appear to disagree about Christ's divinity, they should, it seems, accept that they do not really understand what the other is saying. If they were to gain more insight into each other's conceptual scheme, they would see that their apparent disagreement is really nothing more than a difference. Again, regardless of whether they see this, they should respect each other. And in the case of Phillips' reluctance to make any moral judgement about child sacrifice in a distant culture, it appears that on Harrison's interpretation this reluctance is the appropriate response. It shows that Phillips has recognised the holistic nature of linguistic and perhaps other forms of expression: without knowing a good deal about the surrounding cultural and conceptual context, one cannot be sure what the act, which one hazards to call 'child sacrifice', means for the people involved.

What remains unclear is how the attitudes of toleration and respect are supposed to follow from the appreciation of the diversity of conceptual schemes that Harrison wishes to encourage. One way of reading Harrison's argument would be as advocating the view that incomprehension of another's conceptual scheme is, or ought to be, sufficient in itself to motivate a respectful attitude towards the other's religious beliefs and practices. That, however, would be a surprising claim to make. Indeed, one might presume that incomprehension precludes respect as much as it precludes rebuke. Is Phillips, for example, displaying respect or even tolerance when he says that he would not know what to say about child sacrifice performed in a distant society? He is certainly refraining from condemnation, but so too is he refraining from approval or condonance. None of these attitudes would be apropos in the absence of any clear understanding of what is going on in the other society - of what the behaviour amounts to and of what it means for the participants. Only once one has learnt a good deal more about the society under consideration - and thereby, at least to some extent, entered into or gained a familiarity with their conceptual scheme or schemes-will one be in a

\footnotetext{
${ }^{18}$ The topic of voluntary human sacrifice is controversial. For claims about voluntary sacrifice among the Aztecs, see Prescott (1873, p. 87) and Bakk (1989, p. 49). For perspectives on other cultural contexts, see Wu (1983, p. 44), Law (1985, p. 59) and Willerslev (2009).
} 
position to express either toleration and respect on the one hand or reprobation on the other. That, I think, is the only plausible way of interpreting the point that Harrison is making. To interpret it that way, however, does not give us the conclusion that internalist pluralism necessarily or inevitably promotes 'equal respect' (Harrison 2012, p. 84). It gives us merely the conclusion - perhaps the obvious conclusion - that developing some degree of understanding of another's point of view, and of the conceptual system through which that point of view is articulated, is a necessary condition for either respecting or not respecting the view in question.

\section{Concluding Remarks}

Harrison's interventions in the debate over religious pluralism in the philosophy of religion are to be welcomed, not least for the salutary reminder that they give us that John Hick's 'pluralistic hypothesis' or (to use Harrison's term) 'transcendental pluralism' is not the only pluralist position on offer. The emphasis that Harrison's internalist pluralism places upon the need for a more holistic conception of meaning than is often assumed in such debates is also a move in the right direction: to understand what is being said or done in any mode of life, whether religious or nonreligious, attention to the wider surroundings is of course essential. But there remain problems with the theory of internalist pluralism. Crucial among these is the need for clarification about what the distinction between 'conceptual-scheme targetability' and 'successful conceptual-scheme targeting' really amounts to. My discussion of this distinction resulted in the posing of a dilemma that Harrison's account seems to face. On the one hand, if what it means for someone operating with a first-order conceptual scheme to fail to successfully target a purported object is that the person in question has tried to apply some concept for which there is no relevant target in a given meta-conceptual scheme, it remains unclear why the meta-conceptual scheme's set of concepts should determine the success or otherwise of the application of concepts in the first-order scheme. On the other hand, if what failure to target a purported object amounts to is trying to apply a concept for which there is no appropriate conceptual-schemeindependent object, then it is difficult to see how the idea of successfully or unsuccessfully targeting an object from within a conceptual scheme can avoid collapsing into a version of metaphysical realism; that is, it is difficult to see how it can avoid affirming that there are objects or realities that, without themselves being ontologically dependent on any conceptual scheme, constitute the targets for concepts or statements issued from within conceptual schemes. This seems to be strongly implied by Harrison's talk of the truth or falsity of 'the substantive religious claims' of religious believers being determined by those claims' successfully targeting, or failing to target, something that is not itself constituted by any of the religious conceptual schemes at issue (Harrison 2008, pp. 106-107), and yet Harrison's avowed rejection of metaphysical realism pulls in the other direction.

More generally, I have questioned the way in which Harrison uses examples to illustrate her argument for the enhanced toleration and respect between religions that she supposes internalist pluralism to promote. It is, unfortunately, analytic philosophy's original sin to treat examples as little more than fodder to embellish and support an argument that owes nothing to the examples themselves. A consequence is that the 
examples are left thinly sketched, poorly contextualised and hastily interpreted, and the inferences ostensibly drawn from them are tenuous and ill-supported. The examples that Harrison offers certainly do not support her strong contention that a Christian's affirmation and a Muslim's denial of the divinity of Christ amounts to a mere difference rather than to a genuine disagreement. To say what is going on in a case such as this, we would need to attend to the particularities. I have suggested that Wittgenstein's distinction between disagreements in opinions and disagreements in form of life might provide a useful analytic tool. But even if, in a given case, we were to decide that a disagreement between a Christian and a Muslim is most aptly characterised in terms of a disagreement between forms of life, it remains a disagreement nevertheless. It is unclear how an internalist pluralist analysis is expected to transform the disagreement into a mere difference.

On the whole, the concept of conceptual schemes is not disastrous, but it can be highly misleading, especially if we are tempted to describe 'each conceptual scheme as, in effect, a self-contained world' (Harrison 2012, p. 85). Such descriptions compound the impression that conceptual schemes, and hence the communities who operate with or 'subscribe to' them, are sealed off from one another. Such a picture encourages the sort of claim that Harrison initially makes with regard to Siva - that the qualities of this god cannot intelligibly be discussed in a non-Śaivite conceptual scheme, such as a Christian one. Upon closer inspection, we see that Harrison allows for the possibility of entering into another's conceptual scheme or belief system: of acquainting oneself with the network of concepts, beliefs and practices that give a conception of God the sense that it has. What is at issue is thus something more like a melange of overlapping and interpenetrating schemes, constantly shifting and evolving, with fluid and indeterminate boundaries - not a constellation of self-contained worlds. If the conceptual schemes or faith-stances of religious and cultural communities were well described as selfcontained worlds, it is hard to see how anything even approximating the kind of mutual toleration and respect that Harrison aspires to advance would be possible.

In the end, it remains to be shown why any philosophical theory is needed in response to religious diversity. If the aim is to increase mutual understanding, communication and respect, this may well be assisted by closer attention to the specificities of religious and nonreligious ways of thinking and forms of life, and philosophy has much to offer through cultivating such modes of attention and analysis. Careful scrutiny of examples of disagreement or misunderstanding constitutes a helpful starting point. But the clarificatory work of philosophy is not ultimately in the service of bolstering or facilitating interreligious harmony: if conflicts and antagonisms exist, philosophy can serve to elucidate those conflicts and antagonisms - to allow, as D. Z. Phillips has put it, the 'disputes, and the ways of settling them, along with failures to settle them, to be themselves' (2007, p. 205). But since that task does not involve the construction of a theory, whether externalist, internalist or anything else, the assumption that religious believers require a philosophical theory to help them resolve their differences is one that itself awaits justification. ${ }^{19}$

\footnotetext{
${ }^{19}$ In revising this article for publication, I have benefited from the comments, both critical and constructive, of four anonymous reviewers for the journal. I am grateful both to them and to the editors for enabling me to improve the piece.
} 
Open Access This article is distributed under the terms of the Creative Commons Attribution 4.0 International License (http://creativecommons.org/licenses/by/4.0/), which permits unrestricted use, distribution, and reproduction in any medium, provided you give appropriate credit to the original author(s) and the source, provide a link to the Creative Commons license, and indicate if changes were made.

\section{References}

Bakk, K. R. (1989). Man and his deities. Round Rock, TX: Parker.

Blackburn, S. (1994). The Oxford dictionary of philosophy. Oxford: Oxford University Press.

Blackburn, S. (2005). The Oxford dictionary of philosophy (2nd ed.). Oxford: Oxford University Press.

Blackburn, S. (2016). The Oxford dictionary of philosophy (3rd ed.). Oxford: Oxford University Press.

Burley, M. (2017a). 'The happy side of Babel': radical plurality, narrative fiction and the philosophy of religion. Method and Theory in the Study of Religion, 29(2), 101-132.

Burley, M. (2017b). 'Mountains of flesh and seas of blood': reflecting philosophically on animal sacrifice through dramatic fiction. Journal of the American Academy of Religion, 85(3), 806-832.

Burley, M. (2018). Thickening description: towards an expanded conception of philosophy of religion. International Journal for Philosophy of Religion. https://doi.org/10.1007/s11153-016-9597-7.

Byrne, P. (1995). Prolegomena to religious pluralism: reference and realism in religion. Basingstoke: Macmillan.

Cormier, H. (2015). What is the use of calling Putnam a pragmatist? In R. E. Auxier, D. R. Anderson, \& L. E. Hahn (Eds.), The philosophy of Hilary Putnam (pp. 801-819). Chicago, IL: Open Court.

Davidson, D. (1974). On the very idea of a conceptual scheme. Proceedings and Addresses of the American Philosophical Association, 47, 5-20.

Godlove, T. (1984). In what sense are religions conceptual frameworks? Journal of the American Academy of Religion, 52(2), 289-305.

Godlove Jr., T. F. (1989). Religion, interpretation, and diversity of belief: the framework model from Kant to Durkheim to Davidson. Cambridge: Cambridge University Press.

Griffin, D. R. (Ed.). (2005). Deep religious pluralism. Louisville, KY: Westminster John Knox Press.

Harrison, V. S. (1997). The apologetic value of human holiness. PhD dissertation. Heythrop College, University of London.

Harrison, V. S. (1998). Putnam's internal realism and von Balthasar's religious epistemology. International Journal for Philosophy of Religion, 44(2), 67-92.

Harrison, V. S. (2000). The apologetic value of human holiness: von Balthasar's Christocentric philosophical anthropology. Dordrecht: Kluwer.

Harrison, V. S. (2006). Internal realism and the problem of religious diversity. Philosophia, 34(3), $287-301$.

Harrison, V. S. (2008). Internal realism, religious pluralism and ontology. Philosophia, 36(1), 97-110.

Harrison, V. S. (2012). An internalist pluralist solution to the problem of religious and ethical diversity. Sophia, $51(1), 71-86$.

Harrison, V. S. (2013). Religious diversity. In C. Taliaferro, V. S. Harrison, \& S. Goetz (Eds.), The Routledge companion to theism (pp. 477-490). New York: Routledge.

Harrison, V. S. (2015). Religious pluralism. In G. Oppy (Ed.), The Routledge handbook of contemporary philosophy of religion (pp. 257-269). Abingdon: Routledge.

Heim, S. M. (1995). Salvations: truth and difference in religion. Maryknoll, NY: Orbis Books.

Hick, J. (1995). The rainbow of faiths: critical dialogues on religious pluralism. London: SCM Press.

Hick, J. (2004 [1989]). An interpretation of religion: human responses to the transcendent (2nd ed.). Basingstoke: Palgrave Macmillan.

Kierkegaard, S. (1939 [1843]). Fear and trembling: a dialectical lyric (trans: Payne, R.). London: Oxford University Press.

Knitter, P. F. (Ed.). (2005). The myth of religious superiority: multifaith explorations of religious pluralism. Maryknoll, NY: Orbis.

Law, R. (1985). Human sacrifice in pre-colonial West Africa. African Affairs, 84(334), 53-87.

Norris, C. (2002). Hilary Putnam: realism, reason and the uses of uncertainty. Manchester: Manchester University Press.

Phillips, D. Z. (1970). Faith and philosophical enquiry. London: Routledge and Kegan Paul. 
Phillips, D. Z. (2007). Philosophy's radical pluralism in the house of intellect-a reply to Henk Vroom. In A. F. Sanders (Ed.), D. Z. Phillips' contemplative philosophy of religion: questions and responses (pp. 197211). Aldershot: Ashgate.

Prescott, W. H. (1873). History of the conquest of Mexico (Vol. 1). J. F. Kirk (Ed.). Philadelphia, PA: Lippincott.

Purdum, E. D., \& Paredes, J. A. (1989). Rituals of death: capital punishment and human sacrifice. In M. L. Radelet (Ed.), Facing the death penalty: essays on a cruel and unusual punishment (pp. 139-155). Philadelphia, PA: Temple University Press.

Putnam, H. (1981). Reason, truth and history. Cambridge: Cambridge University Press.

Putnam, H. (1987). The many faces of realism. LaSalle, IL: Open Court.

Putnam, H. (1992a). Realism with a human face. J. Conant (Ed.). Cambridge, MA: Harvard University Press.

Putnam, H. (1992b). Renewing philosophy. Cambridge, MA: Harvard University Press.

Putnam, H. (1994a). Comments and replies. In P. Clark \& B. Hale (Eds.), Reading Putnam (pp. 242-295). Oxford: Blackwell.

Putnam, H. (1994b). Sense, nonsense, and the senses: an inquiry into the powers of the human mind. Journal of Philosophy, 91(9), 445-517.

Race, A. (1983). Christians and religious pluralism: patterns in the Christian theology of religions. London: SCM Press.

Ruhmkorff, S. (2013). The incompatibility problem and religious pluralism beyond Hick. Philosophy Compass, 8(5), 510-522.

Schmidt-Leukel, P. (2005). Exclusivism, inclusivism, pluralism: the tripolar typology-clarified and reaffirmed. In P. F. Knitter (Ed.), The myth of religious superiority: multifaith explorations of religious pluralism (pp. 13-27). Maryknoll, NY: Orbis.

Sharer, R. J. (1994). The ancient Maya (5th ed.). Stanford, CA: Stanford University Press.

Siegel, M. (1941). Religion in western Guatamala: a product of acculturation. American Anthropologist, n.s., 43(1), 62-76.

Willerslev, R. (2009). The optimal sacrifice: a study of voluntary death among the Siberian Chukchi. American Ethnologist, 36(4), 693-704.

Wittgenstein, L. (1966). Lectures and conversations on aesthetics, psychology and religious belief. C. Barrett (Ed.). Oxford: Blackwell.

Wittgenstein, L. (1980). Culture and value. G. H. von Wright \& H. Nyman (Eds.), (trans: Winch, P.). Oxford: Blackwell.

Wittgenstein, L. (1993). Remarks on Frazer's Golden Bough. In J. C. Klagge \& A. Nordmann (Eds.), Philosophical occasions, 1912-1951 (pp. 115-155). Indianapolis, IN: Hackett.

Wittgenstein, L. (1998). Culture and value: a selection from the posthumous remains. G. H. von Wright, H. Nyman \& A. Pichler (Eds.), (trans: Winch, P.). Oxford: Blackwell.

Wittgenstein, L. (2009 [1953]). Philosophical investigations (4th ed.) (trans: Anscombe, G. E. M., Hacker, P. M. S. \& Schulte, J.). Malden, MA: Wiley-Blackwell.

Wu, T.-w. (1983). Lin Biao and the Gang of Four: contra-Confucianism in historical and intellectual perspective. Carbondale, IL: Southern Illinois University Press. 